folk/ed. Derg, 2021; 27(1):101-118

DOI: $10.22559 /$ folklor.1344

Research Article / Araştırma Makalesi

\title{
Kazak Halk Hekimliğinin Kaynağı
}

\author{
Source of Kazakh Folk Medicines
}

\section{Karlygash Ashirkhanova*}

Öz

İnsanlık tarihi kadar eski olan Halk Hekimliği, modern tıp biliminin her geçen gün hızla ilerleyip gelişmesine rağmen bazı hastalıkların teşhisi ve tedavisinde uyguladığ1 pratik yöntemleri ile günümüzde halen işlevselliğini korumaktadır. Zengin ve köklü geçmişe sahip Kazak Halk Hekimliği Kökeni Şamanizm, Totemizm gibi inanç sistemlerine dayanır. Farklı kaynaklardan beslenerek günümüze kadar gelen halk biliminde bakşı, emşi, evliya, tabib, aşık, balger, molla gibi farklı farklı isimlendirilen halk hekimlerinin kökeni incelenmiştir.

Kazak halkının bakşılık geleneği ve halk hekimliğinin ilham kaynağı Dede Korkut ve ezgileri olduğu bilinmektedir. Günümüzde çoğu halk hekimi faaliyetlerini Dede Korkut'un izinden giderek sürdürmekteler. Bu çalışmada, Korkut Atayı kendisine pir ve üstad kabul eden bakşıların bazı bakşılık uygulamalarına yer verilmiştir. Sadece yaşamış oldukları yöre ya da bölgede değil, tüm Kazak coğrafyasında ün salmış olan bakşıların bakşılık Bakşılık geleneğinin tarihi ve gelişim süresi, bakşılığa geçiş kaynă̆ı, bakşıların toplumdaki yeri, görevi ve onlarla ilgili ortaya atılan görüşler, bakşıların giydiği özel kıyafetleri ve ritüel sırasında oldukça önemli, kutsal sayılan aletleri tanıtılıp değerlendirilmiştir. Çalışmamızda Kazak halk hekimliğinin ilk uygulayıcıları olan bakşıların tedavi yöntemlerinin tespiti yapılıp, zaman

Geliş tarihi (Received): 08.06.2020 - Kabul tarihi (Accepted): 28.12.2020

Bu çalışma, "Kazakistan`da Halk Hekimliği”" başlıklı doktora tezinden üretilmiştir. Niğde Ömer Halisdemir Üniversitesi / Sosyal Bilimler Enstitüsü / Türk Dili ve Edebiyatı Anabilim Dalı. 2019.

Dr. Öğretim Üyesi. Kh.Dosmukhamedov Atyrau University. ashirkhanovak@gmail.com. ORCID 0000-0002-6628-5702/ CC BY 
aşamasına uğrayarak şekil değiştirdiği üzerinde durulmuştur. Kültürel kodların belirlenmesi ve uygun şekilde sonraki kuşaklara aktarımı pek çok farklı şekilde gerçekleşetirilebilir. Günümüze kadar gelen kaynakları incelediğimizde çoğu çalışmalar zaman-mekan-şahıs üçlüsü merkez alınarak yapılan çalışmalar olduğunu görmekteyiz. Kazak halk hekimliği yöntemlerinin ve bu işi icra edenlerin külürel geçiş sürecinde var olma mücadeleleri ve sonrasında geleneğin nasıl şekil değiştirdiğini anlamaya çalışmak betimlemek ve bilim dünyasına tanıtmak amaçlanmıştır.

Anahtar sözcükler: Kazak halk hekimliği, şaman, kam, bakşı, bakşılık geleneği

\begin{abstract}
Folk Medicine, which is as old as human history, still maintains its functionality with the practical methods applied in the diagnosis and treatment of some diseases, although modern medical science is advancing and developing day by day. Kazakh Folk Medicine which has a rich and deep-rooted history, is based on belief systems such as Shamanism and Totemism. Today's folklore, by feeding from different sources up to present and named the origins of folk physicians differently, such as bakshi, labor, awliya, medical, lover, balger, molla, have been examined. In Kazakh bakhshi and medicine a large number of folk physicians have lived and are still living, especially the bakhsi, whose inspiration is Dede Korkut and hiz melody. In this study, some applications of bakhsis who accept Korkut Ata as her master are given. The history and development period of Bakhsi tradition not only in the region where they lived, but also in all Kazakh regions, the source of transition to bakhsi, the place, duty and opinions of the Bakhsian and the opinions put forward about them,in society, The special clothes of Bakhsi and the instruments that are considered to be very important and sacred during the ritual will be introduced and evaluated. In our study, it was emphasized that the treatment methods of the Bakshi, which are the first practitioners of Kazakh folk medicine, were determined and changed shape by going through time.The identification of cultural codes and their transfer to the next generations can be realized in many different ways. When we examine the sources that have survived until today, we see that there are studies based on time-spaceperson-trio. It is aimed to understand, describe and introduce to the science world how Kazakh folk medicine methods and those who carry out this work struggle to exist in the cultural transition period and how it changes shape afterwards.
\end{abstract}

Keywords: Kazakh folk medicine, shaman, kham, bakhsi, bakhsi tradition

\title{
Extended summary
}

Treatment tasks are still continuing today with the belief sky god and shamanism / bakshism which are at the root of the Kazakh traditional folk medicine, In our article, Bakshi traditions which are the source of folk medicine titles are handled such as bakshi transition, clothes and tools evident that there are many bakshi who started and continued on their way of bakshism and folk medicine based on Dede Korkut tunes in the history of Kazakh bakshi 
and folk medicine. Today's folk physicians continue and keep them alive. A few of the wellknown bakshis not only in the region where they live, but almost everywhere in Kazakh territory are included in our article. The main subject of mythical stories about Dede Korkut is his search for immortality, eternal life and immortality. The motif of escaping from death in the tunes of Dede Korkut is the appearance of the ideology of bakshism. It is aforementioned that Kazakh bakshi, who came after Dede Korkut, treat his melodies with the kopuz in order to combat death in the process of treatment. We see that the bakshis such as Koylibay, Balakay, Black Mirza, Jaman Sart, Shumen, Dosjan, which became famous in the Kazakh hometown are great bakshis that continued on the trail of Dede Korkut.

According to the sources of researchers at the beginning of XIX-XX century, Kazakh bakshism is known to be weakened with the advent of Islam.

Folk medicine, which was officially restricted in the Soviet Regime, has survived until today struggled to not disappear from the historical scene. Opinions on Kazakh bakshism are widely found in Russian printing until the October plagiarism.

Even if that information is exotic views that are observed by Russian travelers, we can prove that there is valuable information about stature.

In general, Bakshism, as an integral part of ethnographic culture, can be said to play a very impressive role in the molding of the people's traditional worldview, ideology, belief-based customs and healing practices. It is possible to link the emergence of the Kazakh bakshism tradition, which is based on the old system of shamanic religious beliefs, to several sources.

As bakshism in general is a kind of medicine in terms of its main social duty, folk medicine methods and types of religious-magical treatment are at the core of it.

Bakshis' healing practices are based on the mythology and demonology of shamanic religious beliefs. This; human soul, causes of illness, various evil spirits and description of these spirits, search for ways of death, life, immortality, etc. it is directly linked to world view and religious-philosophical insights.

Interest in the Kazakh bakshism tradition started to increase in the world of science in the last quarter of the XVIII century. Western and Russian experts such as scientists, travelers, writers, doctors, officers, etc., who came to Kazakhstan named the bakshis games with concepts such as "magician", "physician", “emissor", “doctor", "prophet”, "fortune teller", as they mostly watch exotic life, in the curiosity of the steppe life.

As the experts found the bakshi games mostly exotic and watched the curiosity of the steppe life, they named the bakshis with concepts such as "magician", "physician", "emissor", "doctor", "seer", "fortune teller". These namings were made based on the games of Bakshis exhibited and the tasks they undertook with the end of the XVIII century and at the turn of the century of XIX The Kazakh bakshism framework was limited functions such as treating, interpreting the future, and finding loss.

Bakshism usually comes from ancestry: from father to son to grandchild. This transition sometimes breaks several generations and reappears in one of the next generations. It is seen that Bakshism's blessing is sometimes passed on to his nephews by his uncle. Often the blessing of stature passes from generation to generation without interruption up to seven hubs. 
The majority of the elected individuals personally experienced the event that there was no escape from the envy of ancestral spirits or jinn. In our article, you can see how the bakshis accept the call to bakshism with examples.

In some selected people, the blessing of bakshism manifests as a child. For this reason, he lived many glances known as "bala bakşı" in different regions of Kazakh territory. The number of those who manifest blessedness as a child among Kazakhs is not small.

In the process of transition to stash, included in the information given in historical sources, visiting the grave of holy personalities, staying a night at the graves, giving hands to dreams are the conditions and conditions that must be fulfilled in order to start the stature mission perfectly.

According to the opinion of historical researchers and ethnographers, the blessing of bakshism manifests in most cases at the age of 30 to 45 years. Usually, the person suffers from the blessing of Bakshism. Behavioral forms such as seeing surreal beings, frequent dizziness, contraction of arms and legs, exposure to spiritual and physical pain, being angry, abstracting yourself in people, avoiding crowded places, and a contemplative attitude are the symptoms observed in candidates. This kind of ailments, which we can call "Bakş1lık hastalıkları", affect some people for a short period of time, and it is seen chronically in some people. Each candidate survives these ailments differently.

When it comes to Turkish shamanism, the three shaman ways mentioned above come together at one point: To become shaman, the illness followed by spiritual depressions, crises, and seizures is the general code of being shaman / bakshi/ Kam. It is also possible that Bakshi's appearance is not very different in society. During the treatment, they wore sacred tools and special clothes and performed rites. When not needed, these tools and apparel treatment tools are kept in bakshi place. We can prove that Bakshi clothes are used especially in animal skin and feather, as a result of being intertwined with nature. In some sources, we encounter in the province where the children facing bakshi, they are afraid and run away. We can say that the clothing of the baksi is old and torn and patched so that the evil spirits run away. In addition to making different sounds, the tools used during the treatment are used to expel bad spirits because they made from cold metals.

Kazak Bakshism was officially banned in 1868 after Russia invaded Kazakh territory. Their main goal is to control infectious diseases in the region before they spread to inner Russia. Many information about Kazakh traditional folk medicine is found in the writings of Russian scientists. The Russification policy implemented in the Soviet Period prevented the development of the national consciousness, language and culture of the local nations. Since the contents of the works, which will be published under the Soviet pressure of seventy years, are constantly examined, there were no great opportunities to investigate the history of folk medicine and to transfer it to the present day.

For Russians, Kazakh folk medicine, developed with traditional techniques of Eastern medicine seemed to overshadow the success of Western medicine. Medical experts who researched Kazakh medicine left the work to historians at this stage. Thus, extensive research 
studies could not be carried out. Folk medicine techniques, which have been going on with the people for centuries, have been largely erased from history and prevented their development and transfer to the present. After Kazakhstan gained independence, folk medicine was examined as a branch of science in established research centers, but could not reach the required level.

\section{Giriş}

İnsanoğlu, yaratıldığı andan itibaren sağlığını korumak ve hastalığı atlatmak gibi önemli bir sorunla karşılaşmaktadır. Biyolojik bir organizma olan insan vücudu, doğal ya da psikolojik etkiler karşısında güçsüz kalarak zarar görmeye meyilli anatomik bir sistemdir. Gördüğü zararları ortadan kaldırmak için tarihî süreç içerisinde deneme-yanılma ve keşif yoluyla birçok yöntem geliştiren insanoğlu, günümüzde vücudunu en küçük bileşenleriyle birlikte ele alan bilimsel tıp bilimini ortaya koymuş bulunmaktadır. Bilimsel tıbbın temelini oluşturan bileşenlerden belki de en önemlisi ve en etkilisi halk hekimliği olarak adlandırılan tedavi uygulamalaridir.

Yaradılışından itibaren kendini ve doğayı tanımaya başlayan insanoğlu, hastalıkların sebepleri ve tedavileri üzerine yaptığı ilk deneme-yanılma tekniği ile kendi başının çaresine bakmaya çalışmıştır. İlk çağlardan günümüze kadar gelen yazı, resim, araç-gereç gibi birçok materyal, o dönem insanının mevcut şartlar içinde, birçok tedavi yöntemini uyguladığını gösterir. Genel olarak bitki ve hayvansal ürünlerden yapılan ilaçlar, insanın dinle tanışması sonucunda büyü, sihir, kurban gibi dinî nitelikli eylemlerle birlikte kullanılarak, aynı doğrultuda farklı tedavi yöntemlerini oluşturur.

Tarihsel süreç içerisinde bu uygulamalar, toplulukların oluşturdukları kültürel unsurların da katılmasıyla yeni bir boyut kazanır ve tedavi türleri farklı uygarlıklarda farklı uygulamalarla yapilagelir.

İlk devirlerde, özellikle Şamanizme inanan Türkler, bu inanç çevresinde oluşan ritüellerle kendine özgü tedavi yöntemleri geliştirir. Günümüze kadar gelen Türk halk hekimliği uygulamalarının büyük çoğunluğunun, Şamanizm etkisinde geliştirilip, zaman içerisinde diğer inanışlara uyarlandığ 1 görülür. Orta Asya'da başlayan Türk tarihi, zaman içerisinde farklı coğrafyalara taşınır. Bu taşınma beraberinde Türk kültürüne özgü unsurların da dünyanın farklı bölgelerine taşınmasına neden olur. Bugün Türklerin yaşadığ 1 tüm coğrafyalarda emçitabiplere (ocaklilara) rastlamak mümkündür.

İlkel toplumda insanlar, hastalıkların kaynağını bilemedikleri için Tanrı'nın buyruklarına uyulmadığında kutun uzaklaşması, kötü ruhlar, yetersiz beslenme, yasakların çiğnenmesi, savaşlar, ay ve güneş tutulmaları, yıldızlar, firtınalar ve şimşek çakması gibi doğa olaylar1; büyü ve büyücüler, devler, cadılar gibi varlıklar ve durumların hastalık nedeni olduğuna inanmışlardır. Hastalıkların tedavisinde ise kaybolan Tanrı kutunu geri alma, ruhlarla iyi geçinme, büyü gibi yöntemlerin yanı sıra bitkisel, hayvansal, madensel ilaçları kullanan kam / şaman, emçi, otacı, büyücü, tabib, sınıkçı gibi adlarla bilinen kişiler halk hekimliği görevini yürütmüştür. 


\section{Korkut Ata'ya dayanan Kazak bakşılığı}

Kazak folklor literatüründe emşi (emçi; ocaklı, izinli, aktar, hekim), tawip (tabip, efsun$\mathrm{cu})$, balger (falcı), otaşı ya da sınıkşı (kırıkçı, çıkıkçı, sınıkçı), molda (hoca, muskacı), şipager (hekim, doktor), demşi ya da dem saluwşı (üfürükçü, muskacı), jırawlar (ozanlar), mıstan (cadı), tamırşı (nabızcı), (Alimbay, 2012:40) gibi farklı adlarla bilinen halk hekimlerinin kökleri İslam öncesi Türk inanç düzenine dayanan tedavi yöntemleriyle büyü uygulamalar1nın ustası kabul edilen Şamanlık / Kamlık / Bakşılık geleneğinin Kazakistan topraklarındaki ardılları olarak adlandırılabilir.

Türk mitolojisinde koruyucu ata ruhlarının büyük bir kısmı Korkut Ata kavramıyla yapısal-işlevsel bağlamda birebir ilişkilidir. Korkut Ata'nın bilinen en eski fonksiyonu bakşı koruyucu ruhu olmasıdır. Onun bu fonksiyonu değişik efsanelerde ölümden kaçma motifine eşdeğer anlam kazanmıştır.

Korkut Ata ile ilgili efsanelerin büyük çoğunluğu benzeri motifin -ölümden kaçma- değişik versiyonlarıdır. Bu efsanelerden birinde Korkut, hem ozan hem aksakal, diğerinde kopuz yapan kişidir. Geri kalanlarında ise evliya, tabip, bakşı şeklinde tezahür eder ve sürekli ölümsüzlük peşindedir. Hatta Korkut ataya atfedilen şiir dizelerinde; o ölümden kaçan ya da ölümün yaklaştığını bildiren bir şahsiyettir. Diyebiliriz ki; o toplumun fizikî (bir tabip olarak hastalara şifa dağıtır) ve manevî (bir evliya olarak olmuşları ve olacakları haber vermekle toplumu içsel olarak geleceğe hazırlar) koruyucusudur. Onun bakşılığı, tabipliği ve evliyalığ1 görünüşü açısından Türk etnik medeniyetinin katmanlarında zaman ve mekan çerçevesinde değişmiş, devrine göre bunlardan biri ön plana çıkmıştır. Bu anlamda Korkut Ata'nın ilk bakışta değişik görünen fonksiyonları biri diğerinin aynı ya da başka basamaklarda semiyotik okunuşudur (Bayat, 2016: 82).

Türk dünyasının muhtelif toplumlarında onun sözlü gelenekte yaşadığını, yaşatıldığını belgeleyen halk anlatıları vardır: Çokan Velihanov'un tespit ettiği bir efsaneye göre " Horhut" adlı şaman Kırgız şamanlarına (baksı) kopuz çalmayı ve türkü söylemeyi öğretmiştir (Özdemir, 2003: 27). Korkut Ata kişiliğinin Türk dünyasında kutsallaşması, yurdun aksakalı ve her şeyi bilen arif insan simgesine dönüşmesiyle açıklanabilir. Bu da onun bakşı icralarından destana kadar Türk kültürünün tüm alanlarında yer almasına neden olmuştur.

Korkut Ata, ölümsüzlüğü toplumdan ayrı, dışarıda aramaktadır. Bu felsefî düşünceye göre insan toplumunda doğum ve ölüm kaçınılmazdır. Sonsuzluk kozmik alemde ya da kutsal alemdedir. Korkut atada ölümün olmadığı bir yerde, gerçek zaman ve mekan dışında bulunmaya can atar.

O, yirmi yaşında iken bir rüya görür. Rüyasında beyaz giysili, ak sakallı bir pîr-i fâni kendisine "kırk yaşından fazla yaşamayacaksın" der. O da bundan sonra dayılarının kendisine hediye ettiği deveye binip ölümsüzlük beldesini aramaya koyulur. Korkut yol alırken önüne kazılı bir mezar çıkar. "Bu da ne?" diye sorduğunda, gaipten bir ses, "Korkut'un mezar" diye cevap verir. Nereye giderse gitsin önüne bu kazılmış mezar çıkar. O da canını kurtarmak için Sır Derya'nın üzerine kilim döşer ve kilimin üstünde oturarak kopuz çalar. Korkut'un canını almaya gelen Azrail gece-gündüz çalınan kopuzun sesinden ona yaklaşamaz ve niçin 
geldiğini unutup, bekler. Efsaneye göre Kazak Edebiyatı'nda “Korkut Küyü” olarak bilinen pek çok ezgi ilk olarak o zaman icra edilmiş yani ortaya çıkmıştır (Şişman, 1998: 51).

Ölümden kaçma ve ölümsüzlüğü arama efsanelerinin ekseriyetinde Korkut Ata'nın ozanlığı ve kopuzunun ölümle mücadele etmesi ön plandadır. Hem tarihî hem mitolojik hem de epik gelenekte Korkut Ata'nın ozanlığı ve ozanların piri olması onun tabipliğinden, evliyalığından, gaipten haber vermesinden, rüya tabir etmesinden daha çok ön plana çıkarılmıştır (Bayat, 2016: 83).

Anadolu'da, ozan-bakşılık geleneğinin XVI. yüzyıldan itibaren yerini âşıklık geleneğine bırakmaya başlaması gibi, Kazak sahasında da bakşılık geleneğini takip eden devrede hem kahramanlık ezgileri, hem de zamanı ve devri değerlendirici destanlarıyla ön plana çıkan jıravların XVIII. yüzyıl sonlarından itibaren yerlerini “akın” adındaki bir başka gelenek temsilcisine bırakmaya başladıkları görülür (Arıkan, 2014: 7).

Bugüne kadar folklor üzerine çalışılmış olan kaynaklarda, Dede Korkut'un ozanlığı, bakşılığı, evliyalığı, tabipliği ve benzeri özelliklerinden her ne kadar bahsedilmiş olsa bile, İbn-i Sina, Ulıkpan Hakım (Lokman Hekim) ve diğer bakşılar gibi herhangi bir hasta üzerinde sağaltma uygulandığına dair bilgilere rastlanmamıştır. Ancak hikayelerinde halk hekimliğine dair birkaç örnek yer almaktadır. Dede Korkut'a “tabiplik” özelliği, hikayelerinde geçen halk hekimliği örneklerinden dolayı verilmiş olabilir kanısındayız. Bu görüşümüzü yukarıdaki Fuzuli Bayat'ın yorumları da onaylamaktadır.

Korkut Ata ile ilgili hikaye ve efsanelerin çoğunun ana teması, ölümsüzlüğü aramaktır. Korkut'un ölümden kaçması ve ölüme çare aramasının temelinde bakşılık ideolojisi bulunmaktadır. Bundan dolayıdır ki Korkut'tan sonraki dönemlerde şöhretleriyle tanınan büyük Kazak bakşılarından Koylıbay, Balakay, Kara Mırza, Jaman Sart, Şümen, Dosjan gibi bakşılar ölümle mücadele ederken Korkut küylerini (ezgi) icra etmişlerdir.

Kazak bakşılarının, hatta Türk halkları bakşılarının piri olarak Korkut Ata kabul edilmektedir. Korkut'un bakşıllı̆ı, bilhassa Kazak topraklarında o kadar iyi korunmuş ki geçmişte yaşamış olan büyük Kazak bakşıları Korkut'u kendilerine pir ve üstad edinmişlerdir.

Kazak bakşılarının piri, atası konusunda görüş tutarsızlığı o kadar yaygındır ki araştırmacılar bu mevzuda farklı şahsiyetlerden bahsetmişlerdir. Örneğin, Ş. Valihanov, "Bağanalı Koylıbay tüm bakşıların piri, koruyucusu, Korkut'tan sonraki en büyük bakşıdır (Valihanov, 1985: 265).” diyerek hem kuşkulu hem de çelişkili bilgi sunmuştur.

Ancak Korkut her türlü tüm bakşıların piri olduğunun tartışılmaması gerek kanaatindeyiz. Korkuttan sonraki dönemlerde her çağın her toplumun önemli büyüğü olduğunu tarihi eserler de kanitlamaktadır.

Zeynolla Sanik ise, Korkut'tan sonraki bakşıların, Korkut'u bir evliya bilerek kendisinden medet umduklarını, Ketbuğa'yı da bakşıların piri ve cin-perilerin atası saydıklarını kaydetmiş ve bu görüşünün doğruluğunu pekiştirmek amacıyla, 1885'te Rusya'nın Barnaul şehrinde Radloff'un neşrettiği “ Obraztsy Narodnoy Literatury Tuyrkskih Plemen” (Türk Boylarının Halk Edebiyatı Denemeleri) adlı eserde yer alan bakşı sarınından örnek vermiştir: 
Öli desem öli emes,

Tiri desem tiri emes.

Ata Korkıt äwliye!

Äweli kuday jın jasağan,

Birinen birin mol jasağan,

Jınnıñ arğı atası - Ketbuğa,

Jin atas1 - sar1 azban,

Äwre k1lma, sen azban!
Ölü desem, ölü değil;

Diri desem, diri değil.

Ata Korkut, bir evliya!

Tanrı evvel cinleri yaratmış ki

Birbirinden üstün yaratmış.

Cinlerin atas1, Ketbuğa:

Cin atası sarı Azban,

Zahmet çektirme, sen Azban! (Sanik, 2017: 45)

Kazak milli arkeoloji ekolünün temelini atan, doğabilimci, etnograf A. Marğulan, "Ejelgi Jır-Anızdar" (Eski Dönem Destan ve Efsaneleri) adlı çalışmasında bakşılar pirinin Korkut olduğunu, destanlardan örnekler vererek savunmuştur.

Su ayağı Korkıt,

Päleketti sen korkit!

Bahs1 piri emes peñ?!

Bahsı baba, sen, kolda!
Suyun sonu Korkut,

Felaketi sen korkut!

Bakşı piri değil miydin?!

Ata bakş1, sen kolla! (Marğulan, 1985: 153).

Korkut'tan sonraki dönemlerde de Kazak topraklarında yaşamış olan ünlü bakşıların çokluğundan söz eden Marğulan, adı geçen eserinde birkaç bakşıya kısaca değinmiştir: "Büyük bakşıların, jıravların, kopuzcuların en çok yetiştiği çevre, özellikle Kıpçakların (XIII-XIX. yy.) arası olmuştur. Bizan starihine geçen Kökem Bakşı; Rum ve Mısır'a elçi olarak gidip gelen Köse, Berende ve Jarık Bakşılar. Bunlardan birisi Mısır'a kopuzunu götürmüştür. Mısırlı fotoğrafçılar fotoğraflarını çekmişler. Kıpçakların arasından çıkan diğer bir ünlü bakşı, Barlık Bakşı'dır. O, İran'a, Gazan Han'a elçi gitmiştir. Bunlar haricinde Sarı Saltık ve Saki Jappar gibi dönemin büyük bakşılarını da söylemek mümkündür” (Marğulan, 1985: 158).

Ş. Valihanov'un Korkut'tan sonraki en büyük bakşı olarak ileri sürdüğü Bağanalı Koylıbay Bakşı'yı konu alan Mağjan Jumabay'ın 1923'te yazdığı "Koylıbaydın Kobızı" (Koylıbay'ın Kopuzu) adlı destanda, bakşının; Nayman boyundan geldiği, bakşılık yetenekleri ve kopuzunun iki yüz atla yarışarak yarışı kazandığı anlatılmıştır

Koylıbay Bakşı'dan sonra Kazaklar arasından çıkan meşhur bakşılar şunlardır: Tiney Bakşı, İztilev Bakşı, Jansaya Bakşı, Kirabay Bakşı, Aspandiyar Bakşı, Darhan Bakşı, İbü Bakşı, Dameli Bakşı, Ajıbay Bakşı vd.

Taranan kaynakların hemen hemen hepsinde bakşı ayinlerine geniş yer ayrilırken, yaşamları ile ilgili çok kısa ve doyurucu olmayan genelleme bilgiler yer almıştır. Bunun nedeni bakşıların toplumdan ayrı; dağ, mağara, orman, nehir ve göl kıyıları gibi ıssız yerlerde hayat sürmüş olmalarından olabilir kanaatindeyiz.

Kazak toprağında Bolșevik rejiminin gelmesi ve onların sömürge politikası, halk arasında hekimliği eskinin kalıntısı diye söylenerek «mollayı kov, kamçıla», sloganıyla elimine edilmişlerdir (Saduakas, 2014: 54). Müslümanlığın yayılmasının kazak halk hekimliğine de olumsuz etkileri olmuştur. Halk arasındaki şifacılar şarlatanlar olarak tanıtılmışıtır. Yinede çoğu zaman halk gerek eski inançları terk etmede zorluk yaşadığından gerek çaresizlikten sabah namazı 
veya akşam namazı sonrası gizlice ocaklarda tedavi aramışlardır. Daha sonrasında Sovyet rejiminin Kazak toprağında hüküm süren sömürge politikaları sonucunda halk hekimliği antik ve çağdışı uygulamalar denilerek halk hekimleri itibarsızlaştırılmış, akabinde yasaklanmıştır.

\section{Bakşılık geleneği}

İlk çağ kabile toplumu ve ilkel toplumun eseri olan bakşıllk; bir kültürel hareket, ideoloji ve toplumsal sistem şeklinde bütün halkların yaşamında vücut bulmuştur. XIX. yüzyılın sonu ile XX. yüzyılın başında araştırılıp yazıya geçirilen bakşılık, Kazak bakşılık geleneğinin İslam'ın getirmiş olduğu kural ve yasaklar yüzünden sürgüne maruz kalarak iyice yıpranan, rengi solan ve adeta son nefesini alıp vermekte olan biçimiydi. Bu düşüncemizi Orta Asya halklarındaki bakşılık sorunları araştıran ünlü bilim adamı V. N. Basilov’un şu sözleri de doğrulamaktadır: Biz, Orta Asya ve Kazakistan'da monoteist dinin hâkimiyeti altında sürünmekte olan bakşılı̆̆ın ancak son dönemine şahit olabildik (Basilov, 1992: 326).

Kazak bakşılığı ile ilgili ilk bilgiler ancak XVIII. yüzyılın II. yarısında ortaya atılmaya başlamıştır. Bunlar, N. Rıyçkov, P. S. Pallas, İ. G. Georgi ve İ. G. Andreev gibi araştırmacıların Kazakistan topraklarındaki bakşılık üzerine kayda aldıkları genelleme bilgilerdir. Kazak bakşıları ile ilgili XIX. yüzyılda ve XX. yüzyılın başlarında yazıya geçirilen ilginç bilgileri A.İ. Levşin, V. V. Radloff, M. Miropiyev, H. Kustanayev, E. Divayev, A. E. Alektorov, İ. Kastaniye vb. araştırmacı bilim adamlarının çalışmalarında bulabiliriz. Sovyet Döneminde Kazak bakşılarının sağaltma uygulamaları ve bakşılık geleneği üzerine değerli araştırmalar yapanlar ise İ. A. Çekaninski, S. Seyfullin, A. Zatayeviç, A. Marğulan, V. G. Erzakoviç, V. N. Basilov, Ä. Tölevbayev, R. Mustafina, K. Baybosınov, R. Kukaşev, E. Tursunov, vd. araştırmacılar olmuştur.

Her ne kadar azımsanmayacak sayıda eser ortaya konulmuş olmasına rağmen Kazak budunbilimci Abilkasımov, Kazak bakşılık geleneğini bir bütün olarak ele alan özel bir çalışmanın henüz ortaya konulmadığını belirtir ve konu üzerine yapılan ilk ve en kapsamlı çalışmanın Ş. Valihanov'un Kazaktardă̆ Şamandıktın kaldiğg (Kazaklarda Şamanlık Kalıntıları) adlı çalışması olduğunu ileri sürer. Bundan sonraki değerli çalışmalar olarak İ. A. Kastaniye'ye ait İz Oblastiy Kirgizskih Verovaniy (Kazak Inançları) ve İ. A. Çekaninskiy'nin hazırlamış olduğu Bahsılık sledi drevnih verovaniy kazahov (Bakşılık: Kazakların Eski Inançlarının Uzantısı) adlı eserleri göstermiştir (Abilkasımov, 1993: 91).

Kazak bakşılık geleneğine ait görüş ve düşüncelere Ekim İhtilali’ne kadarki Rus matbuatında çokça rastlanılmaktadır. Bunların büyük çoğunluğu "egzotik merak" sonucu ortaya atılmış olsa bile geçmişe yönelik bilgiler içermesi bakımından belli bir derecede işe yarayabilir.

Bakş1lık, sağaltma deneyimi olarak çok kadim dönemde ortaya çıkmış, hatta insanoğlunun var oluşuyla birlikte yaşamaktadır. Bunun temelinde halk hekimliği yatmaktadır. Halk hekimliğindeki rasyonel bilgi ve tecrübelerden bakşılar tarafından çokça yararlanılmıştır. Lakin bakşılığı tamamıyla halk hekimliğiyle bağdaştırmak yanlış olur. Çünkü halk hekimliği, halkın yüzyıllar boyunca edinmiş olduğu hastalık türleri ve hastayı tedavi etme yöntemlerine yönelik rasyonel bilgi ve deneyim birikimlerine başvururken, bakşılık iyi-kötü ruhlar, can, 
hami gibi kavram ve varlıklar üzerinde yoğunlaşır. Bakşılığın ikinci bir önemli yönü ise psikoterapistik özelliklere sahip olmasıdır (Tölevbayev, 2013: 182).

Genel olarak bakşılığın, etnografik kültürün ayrılmaz bir parçası olarak halkın geleneksel dünya görüşünün, ideolojisinin, inanca dayalı örf-âdetlerinin ve sağaltma pratiklerinin kalıplaşmasında çok etkileyici rol oynadığını söyleyebiliriz.

Eski şamanlık dinî inançlar sistemine dayandırılan Kazak bakşılık geleneğinin ortaya çıkışını birkaç kaynağa bağlamak mümkündür. Genel anlamda bakşılık, esas toplumsal görevi bakımından bir tür hekimlik olduğundan, onun temelinde halk hekimlik yöntemleri ve dinsel-büyüsel tedavi türleri yatmaktadır. Bakşıların uyguladıkları sağaltma uygulamaları şamanlık dinî inançların mitolojisi ve demonolojisine dayanır. Bu; insan canı, hastalık sebepleri, çeşitli kötü ruhlar ve bu ruhların betimlenmesi, ölüm, yaşam, ölümsüzlük yollarını arama vb. dünya görüşü ve dinî-felsefî anlayışlarla doğrudan bağlantılıdır.

Diğer olaylar gibi bakşılık geleneği de sürekli değişim içindedir: Ortaya çıkma, kalıplaşma, gelişme ve kaybolma gibi dönemler yaşar. Bu yüzden bakşıların toplumdaki yeri, görevi ve onlarla ilgili ortaya atılan görüşler de zamanla farklılık gösterebilir.

Kazak bakşılık geleneğine karşı ilgi, XVIII. yüzyılın son çeyreğinde bilim dünyasında artış göstermeye başlamıştır. Kazakistan'a gelen Batılı ve Rus bilim adamları, gezginler, yazarlar, doktorlar, subaylar vb. uzmanlar bakşı oyunlarını, çoğunlukla egzotik olarak, yani bozkır yaşamına olan meraktan dolayı seyrettiklerinden, bakşıları "sihirbaz", "büyücü”, "hekim”, “emçi”, “tabip”, "kahin”, "falcı” gibi kavramlarla adlandırmışlardır. Bu adlandırmalar, bakşıların sergilemiş olduğu oyunlar ve üstlendikleri görevlere göre yapılmıştır.

XVIII. yüzyılın sonu ile XIX. yüzyıl başındaki Kazak bakşılığı çerçevesi ancak tedavi etme, geleceği yorumlama, kayıp bulma gibi fonksiyonlarla sınırlı kalmıştır.

V. G. Bogoraz-Tan, bakşılık geleneğinin gelişim sürecini aşağıdaki gibi dört döneme ayırmıştır:

a. İlk ve en erken dönemi olan aile içi bakşılık;

b. İkinci dönem uzmanlaşmış bakşılar dönemidir. Ancak henüz toplumdan ayrılmamışlardır. Bu dönemde soydan gelme bakşılık henüz yoktur.

c. Üçüncü dönem kabile toplumuyla alakalı bakşılık dönemidir. Bakşının yardımcısı olur. $\mathrm{Bu}$ dönemde bakşıların, ekonomi ve toplum üzerindeki etkileri daha çok artmıştır ki üretim ve ürünü paylaştırma işlerini yönetirler.

d. Dördüncü dönem olan gelişmiş kabile ve toplumsal sınıf döneminde bakşıllı iyice çökmüştür. Bu dönem bakşılığı, özellikle Kazaklara özgüdür (Bogoroz-Tan, 1914: 153-154).

\section{Bakşının yetişmesi ve bakşılığa geçiş}

Soyunda kut olmayan kağanlık, savında kut olmayan bakşıllı yapamaz, sözünde belirtildiği gibi herkes bakşı olamaz.

Bakş1lık, genelde soydan gelir: Babadan oğula, toruna geçer. Bu geçiş, bazen birkaç nesil ara verir ve sonraki nesillerden birinde tekrar tezahür eder. Bakşılık kutsiyetinin kimi zaman 
dayı tarafindan yeğenlere de geçtiği görülür. Genelde bakşılık kutsiyeti yedi göbeğe kadar ara vermeden nesilden nesile geçer. Bu süreç, Uzakbay adlı bakşının şiirinde işlenmiştir:

Jınnıñ atı Karaman,

Endi kayda baramın

Atamnan kalğan Karaman

Senimenen bolamın
Cinin adı Karaman,

Kurtuluşum yok artık.

Babamdan kalan Karaman

Seninle birlikte yaşarım. (Tölevbayev, 2013: 186).

Bakşılık kutsiyeti, seçilmiş kişide bazen anne karnındayken, bazen de çocukken tezahür eder (Omarbekov, 2015: 67).

Eliade Mircea, Asya'da kişiye şamanlık güçlerinin bağışlanması yollarını şöyle tasnif eder: Şamanlık "mesleğinin" kalıtsal aktarımı (babadan oğula geçmesi) ve, 2) kendiliğinden gelen bir iş çağrısı" ya da "seçilme" dir (Eliade, 1999: 31).

Ecdat şamanın kuş şeklindeki ruhunun ana rahminde olan çocuğa geçtiği ve şaman kaderinin kaçınılmaz olduğu kanıtı, seçimin psikolojik izahıdır. Şaman literatüründe "Iyık Mas" denilen can veya ruh ağacının dallarında yapraklar şeklinde biten müstakbel şamanların ruhları zamanla hamile kadınların rahmine iner. Şaman olacak bebek, anasının karnında iken ağaçtan inen can, vücuduna girer. $\mathrm{O}$ halde seçim bir kaderdir ve şamanın dünyaya gelişinden önce ana rahminde başlamıştır. Ana rahmi öteki dünyayla bağlantılı olduğundan, doğacak şamanla öteki âlem, başlangıçta birbirine bağlıdırlar. Bu alaka, şamanın yuvada terbiye aldığı sürede yenilenir ve yeni bir boyut kazanır. Öteki dünyadan gelen kut, yeniden geldiği yere, şaman gibi kurulmak için döner. Şaman dünya görüşünde kozmik bütünlük, gerçek dünya ile öteki âlemin birbirini tamamlaması şeklinde varlığını sürdürür (Bayat, 2006: 35).

Bu husus, Kazak bakşılarının piri Korkut ile ilgili efsanelerde şöyle anlatılmaktadır: "Annesi, Korkut'a hamileyken yaban eşeğinin sağrı etine aşerir ve bu aşerme bir yıl boyunca sürer. Korkut'u karnında üç yıl taşır ve yılda bir defa doğum sancısı geçirir. Sonunda doğum yapacağı yıl dokuz gün doğum sancısı geçirir. Bu arada üç gün, üç gece karanlık basar, sağanak yağmur yağar ve o kadar şiddetli firtına kopar ki göz gözü göremez hale gelir. Halk çok ama çok korkuya kapılır... Böylesine halka korku salan bir karanlıkta doğduğundan, ona "Korkut" adı verilir” (Marğulan, 1985: 367).

Şamanlık konusunu ana hatlarıyla ele alan bilim adamı Fuzuli Bayat, Rus araştırmacı V. G. Bogoraz'a atıfta bulunarak, bütün ön koşullar dikkate alındığında, bakşılık yeteneğinin, seçilmişlerde doğuştan mevcut olduğunu belirtir ve şöyle devam eder: "Bakşılık yeteneği büyük bir kültür mirasını ve toplumun gizli bilimini korumaya yönelik bir olgudur. Bu yeteneğin felsefi boyutu bakşıların kendilerine verilen bu vergiyi mükâfat olarak değil, bir yük olarak algılamasına dayanır. Toplum da bakşı vergisini ağır bir yük olarak görür” (Bayat, 2006: 35).

Vergi-yük ilişkisini şu şekilde açıklayabiliriz: Vergi göreve çağrıdır ki vergi mükellefi konumunda olan şaman / bakşının, bu "yük"ü (sorumluluk) sırtlaması kaçınılmazdır. Vergi ödemekten kaçınan vergi mükelleflerinin sonunun yasalar çerçevesinde yargılanacağı gibi çağrıyı kabul etmeyen bakşılar da ağır bir şekilde cezalandırılır; bu genellikle ölümle sonuçlanır. Yani çağrı, gönüllü olarak kabul edilmez, zorla kabul ettirilir ve doğal olarak bakşılık ettirgen bir yapı biçiminden edilgen bir yapı biçimine geçmiş olur. Toplum bakşıya, hüküm 
giyen, irade dışı çalıştırılan kişi gözüyle bakar. Bakşılık / Şamanlık üzerine çalışan araştırmacıların büyük çoğunluğu bakşılık görevinin, ilk çağrıdan itibaren ağır sarsıntılarla, ümitsizlikle kabul edildiğinin altını çizmişlerdir.

Ata ruhlarının ya da cinlerin kıskacından kurtuluşun olmadığı olayı seçilmiş bireylerin büyük çoğunluğu bizzat yaşamışlardır. Süymenbay Bakşı'nın bakşılık çağrısını nasıl kabul ettiğini örnek gösterebiliriz.

XIX. yüzyılın sonunda Torğay Vilayeti'nde Süymenbay denen bakşının ayinlerini kayıda geçiren Rusya Coğrafya Derneği'nin üyesi A. E. Alektrov, Süymenbay Bakşı'nın hem baba hem anne tarafında ünlü bakşıların yaşadığını ve babasının da büyük bir bakşı olduğunu anlatmıştır. Babası vefat ettikten sonra cinleri, bakşılık "görev"i ağabeyi Keregebay’a "devretmek" ister ama o, bu görevi devralmak istemez, bakşılığı reddeder ve çok geçmeden ölür. İkinci ağabeyi de bakşı olmak istemez ve o da ölür. Bundan sonra cinler Süymenbay'a musallat olmaya başlar. Bir gün develerini aramaya çıkan Süymenbay, kamışların arasında kaybolur ve karanlık çökene kadar oradan çıkamaz. Etrafina bakınırken bir de ne görsün! Să̆ tarafında başlarına beyaz sarık takan kalabalığın, sol taradında ise büyük bir ordunun kendisine doğru yaklaşmakta olduğunu görür. Çok korktuğundan oracıkta bayılıp düşer. Kendine geldiğinde gece yarısı olmuş ve etrafında kimse yoktu. Evine gelip uyumaya hazırlanırken cinlerin kendi aralarında şöyle fisıldaştıklarını duyar: Süymenbay’ı kendimize başkan seçelim. O, insanları kötü ruhlardan arındırarak tedavi etsin. Hey, Süymenbay, bizi duyuyor musun? Git, insanları tedavi et! Tam o sırada çadırın başköşesinde asılı duran babasının kopuzu çalmaya başlar ve Süymenbay’ın eline gelir. Bu olaydan itibaren ataları ve babasının cinleri Süymenbay'a hamilik etmeye başlar. Süymenbay, o zaman 30 yaşındadır (Alektrov, 1900: 31-32).

Bakşılık çağrısının kaçınılmazlığına değinen halkbilimci Özkul Çobanoğlu, çağrının seçilmiş adayı "bakşı" veya "emçi” olmaya zorladığını belirtir ve gözlemlerini okuyucularına şu şekilde aktarır: "Bakşı veya emçi olmayı reddedenler karşı karşıya kaldıkları amansız hastalık ve benzeri durumun bir neticesi olarak öleceklerdir. Bu nedenle çoğunluk kendisine rüya yoluyla yapılan çağrıyı kabul eder ve yine rüya yoluyla bildirilen yol ve yönteme göre belli ziyaret yerlerini ziyaret edip, kurban kesme ve orada bir gece geceleme gibi bedenini ve ruhsal arınmasını tamamlayarak "görev"e hazır hale gelir” (Çobanoğlu, 2018: 3).

Bazı seçilmiş kişilerde bakşılık kutsiyeti çocukken tezahür eder. Bu nedenle Kazak topraklarının farklı bölgelerinde "bala bakşı" adıyla tanınmış olan birçok bakşı yaşamıştır. Kazaklar arasında çocukken bakşılık kutsiyeti tezahür edenlerin sayısı az değildir. Onlardan biri XIX. yüzyılın 80'li yıllarında dünyaya gelip Kazakistan'ın Arka bölgesinde yaşamış olan Hamidolla Bakşı'dır. O, bakşılığın kendisinde nasıl tezahür ettiğini şöyle anlatmıştır: "On yaşlarında bir çocuktum. Çocuklarla oyun oynuyorduk. Kendimi bir anda çok güçlü hissetmeye başladım. Güreştiğim arkadaşları, hatta benden büyük çocukları bile kolayca yere seriyordum. Meğersem cinler bedenime yerleşmek için beni sıkıştırıyormuş. Yani bu bakşılık kutsiyetinin bende tezahür etmeye başlamasıydı. Bu olaydan sonra ün salmış Koylıbay Bakşı'nın mezarlığında geceledim ve rüyamda el verildi. Böylece bakşıllı̆g başlamış oldum ” (Tölevbayev, 2013: 186).

Tölevbayev'in vermiş olduğu bilgilerde yer alan bakşılığa geçiş sürecinde kutsal şahsiyetlerin mezarının ziyaret edilmesi, mezarları başında bir gece kalınması, rüyâda el verilmesi 
bakşılık görevinin kusursuz şekilde başlatılabilmesinde yerine getirilmesi gereken merhaleler, koşullardır. Bu koşullar, Çobanoğlu'nun (2018: 4) Kazak Halk Kültüründe Kam'dan Baksı ve Emçiye Dönüşümler başlıklı makalesinde şu şekilde yer almaktadır: ...’Bazı bakş1 ve emçiler bu süreci tamamen rüya yoluyla -pratisyenler bunun uyku ile uyanıkık arasında olduğu konusunda ısrar ederler- ve Arslan Baba gibi büyüklerin nezaretinde tamamlandığını anlatmaktadırlar”.

Hamidolla Bakşı, sadece tedavi işleri ve gelecekle ilgili yorumlar yapmayla uğraşmadığını, ayrıca kayıp bulduğunu ve çalınan hayvanların nerede ve kimde gizlendiğini kestirdiğini de anlatmıştır. Cinlerinin kendisine kırk yıl hizmet ettiğini dile getiren bakşı, ölümünden önce Benim cinlerime sahip çıkacak, bu görevi sürdürecek halefim yoktur. Bundan dolayı cinlerim benimle birlikte gidecek demiştir (Tölevbayev, 2013: 186).

Diğer bir kaynakta Hamidolla Bakşı'nın cinleri iyice güçlendiğinde, bedeninin kurşun geçirmediği, karnına bıçak saplanılmadığı ve beline bağlanan ip iki ucundan onar kişi tarafından çekildiğinde, belinin hiç de sıkılmadığını anlatılıyor.

Bedenin her tür dış etkenlere karşı dirençli olmasıyla ilgili hususa açıklık getirmek için yine Şamanlık konusunda Bayat'a başvuruyoruz. Bayat, çağrının rast gele yapılmadığını; herkese bakşılık kutsiyetinin takdim edilmediğini vurgular. Bakşılık görevine çağrılan insanda doğuştan bu sanatın yetenek ve gizemleri gizli bulunur. Örneğin, bakşı görevine çağrılan bireyin ötekilerinkinden bambaşka bir vücut özelliğine sahip olması son derece ilgi çekicidir. Bu tür kişilerde sıradan bireylerde rastlanılmayan iki bedensel farklılık göze çarpar:

Vücuttaki özel bir delik ki buna “oybon” denilir.

Karında olan özel bir yer ki buna "kieli” denilir (Bayat, 2006: 34).

A. Popov'un tespitlerine göre üzeri deriyle örtülmüş bir tür delik olan oybon, bakşının bıçak, hançer, kılıç gibi keskin aletleri sapladığı, ancak kendine zarar vermediği yeteneğini sergilemek için kullandığı özel bir beden uzvudur. Böyle bir deliğin olması bakşının düzenbaz, şarlatan biri olmadığını, gerçekten de bedenine keskin aletleri saplayabilmek becerisinin bulunduğunu haber verir

Bunların yanı sıra çağrı, zayıf, hasta, az konuşan, düşünceli ve garip hareketleri ve tavırları olan insanlara da verilir. Bu ise seçilmiş insanın yukarıda bahsi geçen iki bedensel özelliğini pekiştirir durumdadır. Ayrıca seçilmiş adayın, muhakkak psikolojik bir özelliği de bulunmalıdır. Çünkü bütün zihinsel ve psikolojik ayrıcalıkları şaman / bakşı, eğitimi esnasında almış olur (Bayat, 2006: 36).

Tarih araştırmacısı ve etnograf Omarbekov’un görüşüne göre bakşılık kutsiyeti, çoğu durumda insanda 30 ila 45 yaşlarda tezahür eder. Genellikle bakşılık kutsiyetinin nüfuzunda kişi rahatsızlık geçirir. Gerçek üstü varlıklar görme, sık baş dönmesi, kol ve bacakların kasılması, ruhsal ve bedensel acılara maruz kalma, sinirli olma, insanlarda kendini soyutlama, kalabalık yerlerden uzak durma, sürekli düşünceli bir tavır gibi davranış biçimleri bakşı adaylarında gözlenen belirtilerdir. Bakşılık hastalıkları diyebileceğimiz bu tür rahatsızlıklar bazı kişilerde kısa süre yaşar, bazı kişilerde ise kronik şekilde görülür. Bu rahatsızlıkları her aday farklı şekilde atlatır: 
Bölgenin tanınmış bakşısından el almak;

Kutsal saydıkları atalarının mezarlığında gecelemek;

Bölgenin ün salmış büyük bakşısının mezarını ziyaret etmek;

Uzun süre hasta yatmak ve rüyasında el verilerek iyileşmek (Omarbekov, 2015: 73).

Yaşlara göre bakşılık kutsiyetinin tezahür etmesi konusunda ise, dünya etnografi literatüründe ise 6 ile 50 yaşlarda, bazen daha erken yaşlarda gerçekleştiği iddia edilir. Bu durumda bakşılıkta belli bir yaş sınırının olmadığını söyleyebiliriz ki bu da çağrının özel bir durum sergilediğine işarettir. Her halde görülen şu ki bakşılık kutsiyetinin belirmesi, genellikle cinsel olgunlaşma çağına, yani 20-25 yaş arasına denk gelmektedir. Ayrıca söz konusu kutsiyetin daha geç nüfuz ettiği adaylar da mevcuttur. Kazak bakşıların tarih ve hayatları incelendiğinde, geç yaşta şaman / bakşı olanların genellikle o kadar da güçlü olmayan şaman / bakşılar olduğunu görmek mümkündür.

Bakş1lık kutsiyeti, en iyi şamanlar / bakşılar için üçten beş yaşa kadar; orta düzeyde olan şaman / bakşılar için beş yaştan dokuz yaşa kadar olan dönemde; zayıf şaman / bakşılar için ise 12-18 yaş arası başlar. Bundan sonra fiziki ve psikolojik değişmeler, sarsıntılar, azaplar başlar. Bakşılık pratiğini yürüten günümüz Kazak bakşıları da çağrının yaş bölümünü onaylamaktadırlar.

Kazak bakşı1ığı üzerine Güney Kazakistan’da alan araştırması yapan Çobanoğlu, yaş konusuyla ilgili olarak şunları belirtmiştir: "Emçi veya bakşı gibi bir pratisyen olma sürecinde herşeyden önce "soy" son derece önemli bir etken olarak karşımıza çıkmaktadır. Anne veya baba tarafında bazı hallerde her iki yönde de geçmişte yaşamış "emçi”" ve "bakşı”ların olmas1, bireyin "emçi”" veya "bakşı" olabilmesi sürecini başlatan "ilk çağrı"yı almasında etkidir. Ölen ataların ruhları ve manevi güçleri "ervak" (ervah=ata ruhları veya ruhsal varlıkları) bireyin hayatında bazen 13-15 hatta 7 gibi genç yaşlardan itibaren çeşitli ağır hastalıklar veya “ölümden dönme” halleri ve anlarında ortaya çıkar”(Çobanoğlu, 2018: 3).

Bütün bunlarla birlikte şamanlığg / bakşılığı, çağrı olmadan, yardımcı ruhları (cinleri) bulunmayan, kendi başlarına öğrenenlerin de olduğu görülür. Bu tür "bakşı"ların, taradığımız kaynakların hemen hemen hepsinde, nefsî arzularını ön plana çıkardıkları, halkın cahiliyetini kendi menfaatleri uğruna kullandıkları, yani düzenbaz oldukları ileri sürülmüştür. Bu durumu çalışmasında eleştiren felsefeci K. Şülembayev (Şülembayev, 1978: 49) de onaylar ve o tür şarlatanların özellikle İslamiyet' in yayılmasıyla daha çok arttığını kaydetmiştir. Bunlar bakşılar tasnifinde, büyük ihtimalle ancak ve ancak bakşılık tarih sahnesinde oyun sergilediklerinden, en alt sınıf olan zayıf bakşılar bölümüne dâhil edilmişlerdir.

Halk inancına göre aday; bakşı ya da emçi olacağı sıralarda, bedene yerleşmek isteyen cin ve iyeler (hamiler) tarafından sıkıştırılır. İlk etaplarda bakşı adayı ile yerleşmek isteyen cinler arasında anlaşma sağlanamaz. Çünkü bakşı adayı ilk zamanlar kendisine bakşılık kutsiyetinin yerleşmek istediğinin bilincine varamayabilir. Cinler kimi zaman adayın birkaç yıl hastalık geçirmesine neden olurlar. Bu dönemde bakşı adayı cinlerin dediklerini kabul etmeyerek bakşılık görevi üstlenmemekte epey ısrar eder ama sonunda cin ve iyelere yenik düşer ve bakşı olmayı kabul eder. Böylece hastaları tedavi eder, fala bakar ve zaman içerisinde bakşı ayinlerini de yapmaya başlar (Kondıbay, 2004: 298). 
Bazı bilim adamları şamanların kendi kendine asabi-isterik bir karakter sergilediği görüşündedirler (Tokarev, 1964: 294). Özellikle kaydetmek gerekir ki şaman/bakşı hastalığ1 tipindeki hastalık, kutsiyet tezahür eden/çağrı alan bütün adaylarda; halk hekimlerinde, bakşılarda, ozanlarda, jıravlarda, falcılarda vb. görülmektedir. Ruhların/ervakların/cinlerin dilinden şiir ya da dua söyleyen, kozmik bilgileri sembolik bir dille topluma ileten, tedavi eden, gelecekten haber veren bu kişilerin durumunu hastalık adı altında değerlendirmek değil, etno-psikolojik kültür hadisesi olarak değerlendirmek doğru olur.

Bakşı ya da emçi olmak, Türk ya da daha genel anlamda Asya şamanizminde bireyin soyuna bağlı olarak kabul etmesi teklif edilen bir misyon ya da göreve dönüşmüştür. Kendisine soyundaki "ervak"ları tarafından "kut" verilerek teklif edilen bu görevi bakşı olmayı reddeden "bakşı” adayını "kut-urmakta” ve o kişi kudurarak ölmektedir. Bakşı ya da "emçi” de "ölümle" karşı karşıya olduğu bir anda "ervak" tarafından kendisine teklif edilerek verilen görevi kabul etmemeleri halinde kaderine terk edilerek ölecektir. Ancak görevi kabul ettiği için ölümden dönen, pek çok anlatmada ölmeden ölen, ahirete veya öteki dünyaya gidip gören ve görevi kabul ederek tekrar insanlar arasında "bakşı” ve "emçi” olarak yaşayan pratisyenlerin aynı kavramsallaştırma doğrultusunda tematik, sosyal, kültürel ve işlevsel bir süreklilik gösterdiği açıktır (Çobanoğlu, 2018: 4).

Bu bağlamda bakşılık, adeta soya bağlı olarak yaratılışla birlikte dünyaya gelindiğinde devralınan "kamuya hizmet etmeyi" ve onu "korumayı" esas alan bir kutsal özün, "ervak"ın yeni etözlerde ya da bedenlerde, yeni nesilleriyle kamuya hizmet etmeye adanmasıdır denilebilir. Bu bildiğimiz "ruhgöçü”nü çağrıştıran sözlerle kastımız bedenden bedene göçen/geçen bir ruh anlamında "tenasüh" değildir.

Fuzuli Bayat, şaman seçilmenin genel hatlarıyla üç yolla gerçekleşeceğini ileri sürmüştür:

Soyla geçen şamanlık görevi: Baba hattı ile olduğu gibi ana hattı ile de geçebilir. Bu durumda aileden birinin veya bir kaçının şaman olması ve ecdat şamanın kendi soyundan birini şamanlık görevi için seçmesi söz konusudur. Ecdadı şaman olmayan birinin ruhlar tarafından şamanlık görevine seçilmesi. İnsanın kendisinin şamanlık yolunu seçmesi ve şaman sırlarını öğrenmek için uzun bir mesafe kat etmesi (Bayat, 2006: 27).

Diğer inanç sistemlerinde olduğu gibi, şamanlıkta da iç ve dış taraflar görülebilir. Bin yıllar boyunca şamanlığın felsefî temelleri ve ritüel pratiği usta şaman tarafından adaya sözlü bir biçimde öğretilmiştir. Ayrıca şamanların rüyâlar ve cinler aracılığg ile bu mesleğin gizli sırlarını benimsediklerine de rastlanmaktadır. Bunun başlıca nedeni, mürekkep şaman gerçeklerinin (bu gerçeklik şamanlığın çok tabakalı olmasıyla ayırt edilir) rasyonel izaha uymamasıdır. Gizli bilginin mevcutluğu onunla bağdaşır ki şaman seyahatleri her zaman korkulu ve gözlenilmez olmuştur. Bu nedenle bu tür seyahatler her zaman büyük manevi güç, fiziki sağlık ve ahlaki temizlik talep etmiştir (Anjiganova, 2002: 105).

Şamanlığa geçişin alameti olan and töreninde şamanlar iyi ve kötü iyelerle aralarındaki ilişkinin sınırlarını öğrenirler. Mücadele edecekleri animistik güçleri öğrenirler. Faaliyet alanları hakkında fikir sahibi olurlar. Bu sebeple şamanlığa geçişteki and töreni şamanlık yetilerinin bağlı olduğu referansları gösteren bir kut törendir. 
Bakş1lık, ecdattan evlada verilen mirastır. Sinir sistemi bozukluğu olan ebeveynler sıklıkla kendilerini bakşı, emçi, tabip bilinçli bulmaktadırlar. Demek, bir çocuğun hastalığı soydan alması normaldir. Bu durumda, kendilerini özel kalitede buluyorlar (Çekaninskiy, 1929: 78). Ancak, bakşılık sadece atadan çocuğa verilen miras olarak kabul edilmez. Bir bakşının dediklerine göre, meğer ebeveyn çocuğunu bakşı olmasını isterse, sürüden bir erkek koyun seçer. Onun ipine yanmış kumaşı bağlar. Zamanı gelince kumaşı alıp kuzuya koyar. Daha doksan gün sonrakuzuyu kesip, etini yoksullara dağıtır. Derisini mollaya verir. Kanını keçe evin yanına gömer. Kürek kemiği devenin derisine bağlayıp, baksı çocuk isteyen aileye verir. Çocuk doğar doğmaz ilk önce meme emmeden, kürek kemiği emer (Çekaninskiy, 1929: 99).

Genel olarak Türk kültüründe soyla geçen ve ecdat şaman ruhunun göreve çağırdığı şamanlık öğesi daha çok kabul görmüş ve şaman folklorunda önemli bir yer oluşturmuştur.

Türk şamanlığı söz konusu olduğunda, yukarıda bahsi geçen üç şaman olma yolu bir noktada birleşir: Şaman olmak için ruhi depresyonlarla, krizlerle, nöbetlerle izlenen hastalık şaman/bakş1/kam olmanın genel kodudur.

K1saca bakş1lığa geçiş prosedürü; hastalanma, çă̆rı alma, çağrıyı kabul etme, manevi olarak temizlenme, hizmete hazır hale gelme ve yetkinleşme gibi alt başlıklarla ifade edilebilecek aşamalardan oluşur. Bilindiği gibi, Eliade'nin konuyu da bilim dünyasında meşhur eden ünlü çalışması "Şamanizm”den beri söz konusu aşamaların aynen başta Sibirya olmak üzere Türk, Altay, Moğol, Buryat hatta Asya bakşılık geleneklerinde vücut buluşudur. Ayrıca yukarıda bahsi geçen "bakşı hastalıkları"nın ortaya çıkması, temsili olarak "etlerin kemiklerden" ayrılarak temizlenmesi, bakşı olacak kişinin "yardımcı ruhlar edinmesi” ve ata ruhları nezaretinde eğitilip yetiştirilmesi ve en sonunda bazı geleneklerde bir koç kurban edilerek kamuya bakşı olarak hizmet etmeye başlamasıyla alakalı çok geniş bir literatür bulunmaktadır.

\section{Bakşı kıyafeti ve aletleri}

Önce bakşıların kıyafetleri ve ritüel sırasında kullandıkları araç-gereçlerden ve başvurdukları yardımcı ruhlardan bahsetmek yerinde olacaktır.

Bakşıların tedavi sırasında kullandığı kutsal araçların hepsi asai-musei diye adlandırılmıştır. Şamanlık inanıında Bakşılar, Asai gökteki, Musei ise yerdeki ruhları yardıma çağırırlardı (Kul Muhammed, 2005: 68). Bu aletleri kullanan bakşılar insanlara psikolojik bir etki yaparak tedavi ederlermiş. Üzerine giydikleri bol kesim giysiler ve ses çıkaran çıngıraklarla korku getirip hastalığı kovmaya çalışırlardı.

Bakşılar yama işi kaba, kuş tüylü ve hayvan derisi giyisiler giyer ve kemiklerinden kolye takarlardı. Şamanların böyle giyinmesinin sebebi; yaşamın yoksulluk, doğa ve hayvanlarla iç içe olduğu fikrini vermek içindi. Kazak bakşılarının giyimi genelde bayan elbisesi tarzında dikilmiş üzerine çeşit çeşit kuş tüyleri, çanlar,muska, kolye, hayvanların pençeleri dizilmiştir. Şamanların elbisesinde kadın memesine benzetip dikilen dikişler olur. Bazı erkek bakşıların bakşılığa geçiş döneminde bayan elbisesi giydikleri bilgileri mevcuttur (Alimbay, 2012: 370). İ. Kastaniyenin yazılarında ise bakşının yeninde puhu kuşu dikildiğini veya elinde puhu kuşu tüylü sopası olduğu söylenir. Bakşılık anaerkil döneminden kadınların görevi olduğun- 
dan erkek bakşı kendisine bakşı ruhu girip bakşı olma kabiliyetine sahip olana kadar cinleri kaçırmamak niyetiyle bayan elbisesi giymiş kaanati yaygındır.

Şamanların baş giyimi Amerikalı kızılderililerin baş giyimi tarzında kuş tüyleri dizilmiş şekilde uzun olur. Cinlerle savaştığı zamanlar bakşı giyimlerinin koruyucu özelliğe sahip olduğu söylenir (Abdizgaziulı, 2010: 45). Baş giyimlerinde olduğu gibi ayakkabıları da kuş formu veya üçgen şeklinde metal plakalarla süslenmiştir. Bu metal plakalar farklı sesler çıkarırlar. Bol miktarda metalın kullanılması kazakların yaşam kültüründe hala devam etmektedir. Metal kutsal sayılır (Tohtobayeva, 2017: 45).

Son zamanlardaki Kazak bakşıları halkla iç içe yaşayıp, ailelerine ve günlük işlere öncelik vermişlerdir. Yine de zaman zaman halktan gelen taleplere göre bakşılık görevlerini de sürdürdüler. Günümüzdeki bakşılarımızın da giyimlerinde çok farklılıklar yok. Sadece geçmişte bakşılar sarı rengi çok kullandıkları bilinir ama şimdilerde beyaz rengi ve milli nakış dikişli kaftan veya yelek giydiklerini görmekteyiz.

Araç-gereçler; rituel icrasında son derece önemli bir yer tutar; oyunun etkili, kusursuz gerçekleşmesinde ve yardımcı ruhların, cinlerin, ata ervaklarının ve kut-iyelerin (hamilerin) çağrılmasında büyük rol üstlenen olmazsa olmaz tamamlayıcı enstrümanlardır. Bu enstrümanlardan istifade edilmeyen bakşı oyununu düşünmek bile imkânsızdır. Kazak bakşılarının ritüel esnasında yararlandıkları araçları aşağıdaki gibi tasnif edebiliriz. Araç-gereç türleri, başta Tölevbayev (2013: 69) ve Abilkasımov (1993: 127) olmak üzere diğer araştırmacıların ortaya koymuş oldukları çalışmalardan tespit edilmiştir.

Müzik enstrümanı olarak; aynalı kopuz, dombıra, davul, çıngırak.

Korkutma ve ürkütme araçları olarak; “asa”, “ateş”, "kamçı”, “bıçak”, "hançer”, “topuz”, “tokmak”, “orak”, “tırpan”, “kazma”, “çapa” vb. kullanılmaktadır.

Bunlar bakşıların başlıca araçlarıdır. Bunun yanı sıra ek olarak kullandıkları malzemeler de mevcuttur: Fala bakmak için kullandıkları 41 kumalak, koyunun kürek ve kaval kemikleri, çeşitli muskalar, banotu (gonca) bitkisi ve ardıç.

\section{Sonuç}

Halk hekimliğinin temeli olan bakşılık geleneği, Sovyet döneminde yasaklanmış, dolayısıyla zayıflatılmıştır. Zaman zaman yok olma riskiyle karşı karşıya kalsa da geleneksel Kazak toplumunda bakşıların sosyal statüsünün yüksek olması, gerçek bakşıların kendi sanatına saygı göstererek halkın güvenini kazanmaları ve yararlı yöntemlerin uygulanması çağdaş yaşamımızda halk, etnografi kültürün unsuru bu geleneği hayatta tutmayı başarmış olsa da az bilinen geleneklerden biridir. Kazak Türkleri bağımsızlıklarını kazandıktan sonra bakşı kültürü bilimsel açıdan incelenmeye başlanmıştır. Ancak bu konuda yapılan çalışmalar yetersiz kalmıştır.

Kökeni antik Türk mitolojisine dayanan, yüz yıllar boyunca halk arasında deneme yanılma yoluyla gelişen Kazak halk hekimliği ne kadar zorluk görse de günümüze kadar gelmeyi ve modern tıbbın bir ana bilim dalına dönüşmeyi başarmıştır. Günümüzde Çin Halk Cumhuriyeti'nde yaşayan Kazaklar tarafından kurulan ve bakşı gelenekleri uygulanan tıbbi merkezler resmi olarak çalışmaktadır. Çin devleti tarafından da destek gören Kazak halk he- 
kimliği merkezleri büyük ilgi görmektedir. Kazakistan 1991 de bağımsızlığını aldığı zaman tıp fakültelerinde doğu tıp bölümleri açılmıştır. Maalesef Kazakistan'da bu iş resmi olarak devam ettirilmemiş ve sadece halk arasında varlığını korumaya mahkum edilmiştir. Kazak bakşılığı insanlara sadece yardım etme niyetiyle tedavi hizmetleri sunmaktadır.

\section{Notlar}

1 Çalışmada Kırgız ifadesi geçiyor. Bu ifade 1920 yılı Ruslar tarafından Kazaklar Kırgız diye adlandırıldığını belirtmek gerekmektedir. 1925 yıla kadar Rus oryantalistleri tarafindan Orta Asya' daki iki milletin birisini "Kırgız" ikincisini de "Kara Kırgız" diye aşağılamış niyette adlandırılması söz konusudur.

\section{Kaynaklar}

Abdigaziul1, B. (2010). Kazak adebiyeti ensiklopediyak anıktamalık. Almatı: Aruna.

Abilkasimov, B. (1993). Telkonir. Almat1: Atamura.

Alimbay, N. (2012). Kazaktın etnografiyalık kategoryalar, uğımdar men ataularının dasturli juyesi. Ensiklopedi. C1, Almat1: DPS.

Anjiganova, L. (2002). Şamanizm kak predmet mejditsiplinarnogo issedovaniye. Abakan.

Arıkan, M. (2014). Başlangıçtan 20. yüzyıla Kazak jırav ve akınları. İstanbul: Gece.

Basilov, V. (1992). Şamanstvo u narodov sredney Azii i Kazahstana. Moskva: Nauka.

Bayat, F. (2006). Ana hatlarıyla Türk şamanlı̆̆ı. İstanbul: Ötüken.

Bogoraz, V. (1914). K psihologi şamanstvo u narodov severno-vostoçnoy Azii. Etnografiçeskiye obozreniye dergisi, ss.1-2.

Çekaninskiy, İ. (1929). Bahsılık sledi drevnih verovaniy kazahov. Semey.

Çobanoğlu, Ö. (2018). Kazak halk kültüründe "Kam”dan "Baksı" ve "Emçiye” dönüşümler. $A v$ rasya Uluslararası Araştırma Dergisi, S. 6 (15), ss. 1.

Eliade, M. (1999). Şamanizm. İ. Birkan (çev). Ankara: İmge.

Kondıbay, S. (2008). Kazak mifologiyasına kirispe. Almatı: Arıs.

Kul Muhammed, M. (2005). Kazak medeniyeti. Almat1: Aruna.

Marğulan, A. (1985). Ejelgi jır, anızdar. Almat1: Jazuwş1.

Omarbekov, T. (2015), Ortalık Aziya köşpelileri örkeniyetinin tarihı-2. Almatı: Kazak Milli Üniversitesi.

Özdemir, H. (2003). Dede Korkut'un kişiliği ile ilgili efsaneler. Türkoloji Dergisi, (16. cilt), S. 2, ss. 22. Ankara: Dil ve Tarih Coğrafya Fakültesi.

Saduakas, E. (2014). Tağılımğa tağzım, Almatı: Dawır.

Sanik, Z. ve Zeynollakızı, J. (2017). Kazak etnografiyası. Almatı: An Arıs.

Şişman, B. (1998). Kazakistan'da Korkut Ata ile ilgili söylenceler. Milli Folklor Dergisi, S. 37, ss. 51.

Şülembayev, K. (1978). Tawipşildik degen ne? Almatı: Kazakistan.

Tohtabayeva, J. (2017). Etiketniye normı kazahov. I Pub Dijital.

Tölevbayev, A. (2013). Kazak halkı etnografiyasının maseleleri. Almatı: Service Press.

\section{Elektronik kaynaklar}

Köse, N. (2002). Kazakların halk hekimliğiyle ilgili bazı pratikler hakkında. Türk Kültürü Dergisi. Ankara Üniversitesi Basimevi. http://turkoloji.cu.edu.tr/HALKBILIM/nerin_kose_kazak_halk_hekimligi.pdf (Erişim 20.08.2019) 